\title{
Influence of Linking Group Orientation on Mesomorphism of Two Aromatic Ring Mesogens
}

\author{
L. K. Ong ${ }^{1}$ and S. T. $\mathrm{Ha}^{2,3}$ \\ ${ }^{1}$ Faculty of Engineering \& Science, Universiti Tunku Abdul Rahman, Jalan Genting Klang, Setapak, Lumpur, 53300 Kuala, Malaysia \\ ${ }^{2}$ Faculty of Science, Universiti Tunku Abdul Rahman, Jalan Universiti, Bandar Barat, Perak, 31900 Kampar, Malaysia \\ ${ }^{3}$ Centre for Biodiversity Research, Universiti Tunku Abdul Rahman, Jalan Universiti, Bandar Barat, Perak, 31900 Kampar, Malaysia
}

Correspondence should be addressed to S. T. Ha; hast@utar.edu.my

Received 14 May 2013; Accepted 27 June 2013

Academic Editor: Iciar Astiasaran

Copyright (C) 2013 L. K. Ong and S. T. Ha. This is an open access article distributed under the Creative Commons Attribution License, which permits unrestricted use, distribution, and reproduction in any medium, provided the original work is properly cited.

A new homologous series of alkyl $4-\{[(4$-chlorophenyl)imino]methyl $\}$ benzoates were prepared, and all the members are differentiate by the alkoxy chain length, $\mathrm{C}_{n} \mathrm{H}_{2 n+1} \mathrm{O}$, where $n=2-7,9,11,13,15$. Their phase transition behaviors and mesophase characteristics were studied by differential scanning calorimetry (DSC) and optical polarizing microscopy techniques. DSC thermograms show direct isotropization and recrystallization during heating and cooling processes, respectively. The crystal phase changed directly to dark area textures (isotropic phase) without displaying any mesophase. The mesomorphic properties of compounds studied are strongly dependent on the orientation of the ester linkage. Reversed ester linkage has caused depression of mesomorphic property in the compounds studied.

\section{Introduction}

Development of liquid crystal science and technology has led to the study of numerous newly synthesized mesogens, in particular, thermotropic liquid crystals $[1,2]$. Most thermotropic liquid crystals are rod-like molecules having core system composed of two or more aromatic rings and one or more flexible terminal chains. Molecules containing $\mathrm{C}=\mathrm{N}$ double are known as Schiff base, a well-known linking group used in connecting two core groups. It is formed by a reaction of primary amine and aldehyde. Though it provides a stepped core structure, it retains molecular linearity, hence providing higher stability and enabling mesophase formation [3,4]. Schiff base system has received overwhelming responses ever since the discovery of MBBA which exhibited nematic phase at room temperature [5]. Several studies have been conducted on Schiff base esters owing to their interesting properties and considerable temperature range [6-15].

In recent studies $[16,17]$, modification on orientation of ester linkage between aromatic units led to interesting variations of mesogenic properties in bent core molecules. Schiff base 4-chlorobenzylidene- 4 ' alkanoyloxyanilines with ester linkage exhibited smectic A and B phases [18]. In this continuation study, we aim to change the orientation of ester linkage on the existing system and to study the influence of reversed ester linkage on mesomorphism of Schiff bases. In spite of the structural similarity, the smectic nature of the series is quite different.

\section{Materials and Methods}

4-Carboxybenzaldehyde, 4-chloroaniline, 4-dimethylaminopyridine (DMAP), N,N-dicyclohexylcarbodiimide (DCC), and straight chain alcohols $\left(\mathrm{C}_{n} \mathrm{H}_{2 n+1} \mathrm{OH}\right.$, where $n=2-7,9$, $11,13,15)$ were obtained commercially. The synthetic route for the title compounds is illustrated in Scheme 1.

Electron ionization mass spectrum (EI-MS) was obtained using a Finnigan MAT95XL-T mass spectrometer operating at $70 \mathrm{eV}$ ionizing energy. FT-IR data were acquired on Perkin Elmer 2000-FTIR spectrophotometer in the frequency range of $4000-400 \mathrm{~cm}^{-1}$ with samples embedded in $\mathrm{KBr}$ discs. NMR spectra were recorded in deuterated chloroform by utilizing Bruker Avance $400 \mathrm{MHz}$ NMR spectrometer with TMS 


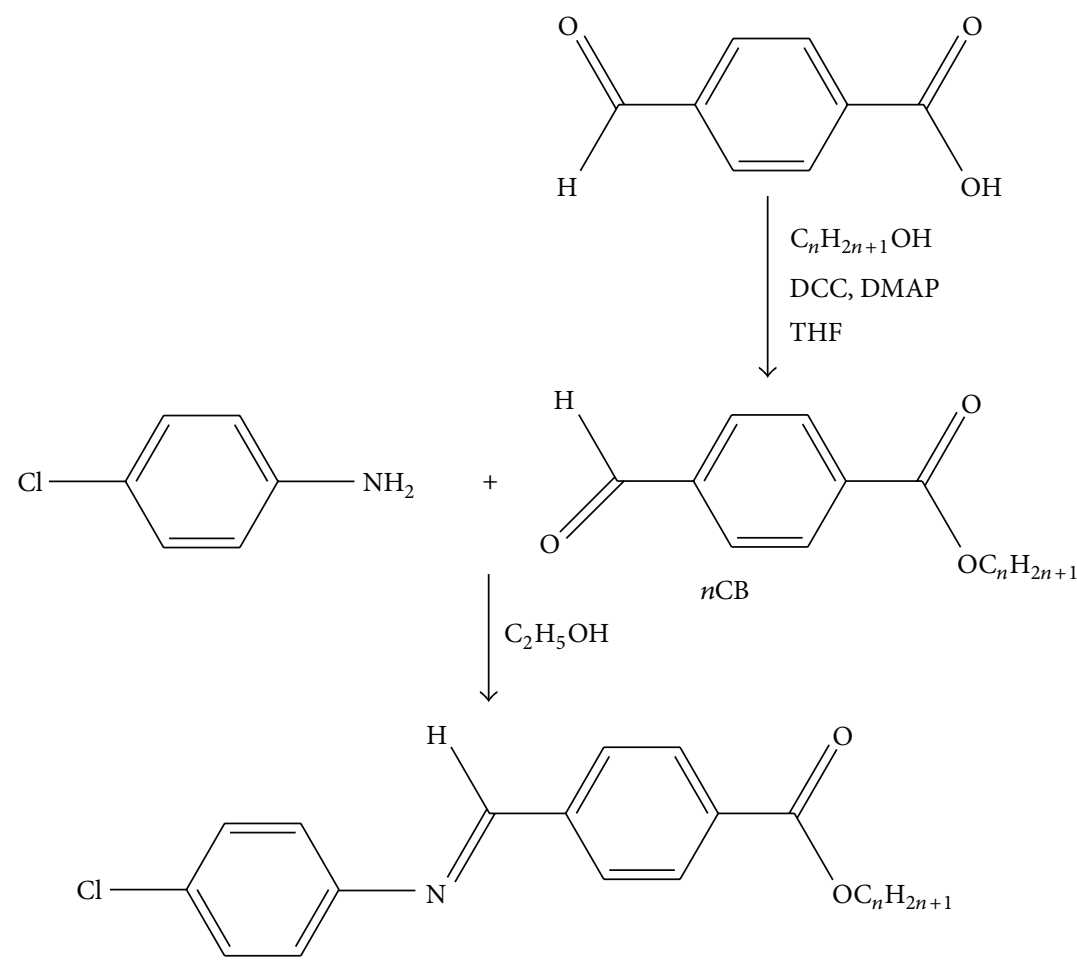

$n$ ClCBA (where $n=2-16$ )

SCHEme 1: Synthetic route of alkyl 4-\{[(4-chlorophenyl)imino]methyl\}benzoates.

as internal standard. The phase transition temperatures were measured by Mettler Toledo DSC823 Differential Scanning Calorimeter (DSC) at a scanning rate of $10^{\circ} \mathrm{C} / \mathrm{min}$. Liquid crystalline properties were investigated using a Carl Zeiss Polarizing Optical Microscope (POM) attached to a Linkam Hotstage.

2.1. Synthesis of Alkyl 4-Formylbenzoates, $n C B$. A mixture of 4-carboxybenzaldehyde ( $1 \mathrm{mmol})$, straight chain alcohol (1 mmol), and DMAP $(0.02 \mathrm{mmol})$ was dissolved in tetrahydrofuran $(20 \mathrm{~mL})$ in a round bottom flask. DCC $(1 \mathrm{mmol})$ in $5 \mathrm{~mL}$ THF was added dropwise to mixture and stirred at $0^{\circ} \mathrm{C}$ for an hour and then stirring was continued at room temperature for three hours [12]. The reaction mixture was filtered and excess solvent was removed by evaporation. The white intermediate was recrystallized with hexane until transition temperature remained constant.

\subsection{Synthesis of Alkyl 4-\{[(4-Chlorophenyl)imino]methyl $\}$ ben-} zoates, $n C l C B A$. A solution of alkyl 4-formylbenzoate $(1 \mathrm{mmol})$ and 4 -chloroaniline $(1 \mathrm{mmol})$ in ethanol $(50 \mathrm{~mL})$ was heated under reflux for three hours. The product obtained was repeatedly recrystallized with absolute ethanol whereupon the pure compound was isolated as a yellow solid.
The IR, NMR $\left({ }^{1} \mathrm{H}\right.$ and $\left.{ }^{13} \mathrm{C}\right)$, and mass spectral data of the representative compound, $11 \mathrm{ClCBA}$, are summarized as follows.

11ClCBA: EI-MS $m / z$ (rel. int. \%): 413.2(53) $[\mathrm{M}]^{+}$, 260.0(100), 242.0(37), 215.0(38); IR (KBr) $v_{\max } \mathrm{cm}^{-1}: 2953$, 2919, 2848 (C-H aliphatic), $1714(\mathrm{C}=\mathrm{O}), 1625(\mathrm{C}=\mathrm{N}), 1284$ (C-O); ${ }^{1} \mathrm{H}$ NMR $\left(400 \mathrm{MHz}, \mathrm{CDCl}_{3}, \delta \mathrm{ppm}\right): 0.90(\mathrm{t}, 3 \mathrm{H}$, $\left.\mathrm{CH}_{3}\right), 1.28-1.47\left\{\mathrm{~m}, 16 \mathrm{H}, \mathrm{CH}_{3}\left(\mathrm{CH}_{2}\right)_{8}-\right\}, 1.80$ (quint, $2 \mathrm{H},-$ $\left.\mathrm{CH}_{2} \mathrm{CH}_{2} \mathrm{O}-\right), 4.36$ (t, $\left.2 \mathrm{H},-\mathrm{CH}_{2} \mathrm{O}-\right), 7.19$ (d, $\left.2 \mathrm{H}, \mathrm{Ar}-\mathrm{H}\right)$, 7.39 (d, 2H, Ar-H), 7.98 (d, 2 $\overline{\mathrm{H}}, \mathrm{Ar}-\mathrm{H}), 8.16$ (d, 2H, Ar$\mathrm{H}), 8.33(\mathrm{~s}, 1 \mathrm{H}, \mathrm{CH}=\mathrm{N}) ;{ }^{13} \mathrm{C}$ NMR $\left(100 \mathrm{MHz}, \mathrm{CDCl}_{3} \delta \mathrm{ppm}\right)$ : $14.08\left(\mathrm{CH}_{3}\right), 22.66,26.02,28.70,29.27,29.31,29.51,29.58$, 31.89 for methylene carbons $\left[\mathrm{CH}_{3}\left(\mathrm{CH}_{2}\right)_{9}-\right], 65.50\left(-\mathrm{CH}_{2} \mathrm{O}-\right.$ ), 122.37, 128.66, 129.33, 129.96, 132.07, 132.98, 139.62, 149.99 for aromatic carbons, $159.41(\mathrm{CH}=\mathrm{N}), 166.08(\mathrm{C}=\mathrm{O})$.

\section{Results}

Spectral characteristics of $n$ ClCBA were studied by using mass spectrometric and spectroscopic methods. The percentage yields and the infrared data are tabulated in Table 1. The purity of the products was analyzed by thin layer chromatography (TLC) on silica gel plates and was chromatographically pure, as indicated by a single spot. The phase transition temperatures and their associated enthalpy changes during heating and cooling cycles are tabulated in Table 2. Representative EI mass spectrum is depicted in Figure 1. DSC 
TABLE 1: Percentage yields and IR frequencies of alkyl 4-\{[(4chlorophenyl)imino]methyl\}benzoates.

\begin{tabular}{lccccc}
\hline \multirow{2}{*}{ Compound } & $\begin{array}{c}\text { Yield } \\
(\%)\end{array}$ & $v(\mathrm{C}-\mathrm{H}$ aliphatic $)$ & $v(\mathrm{C}=\mathrm{O})$ & $v(\mathrm{C}=\mathrm{N})$ & $v(\mathrm{C}-\mathrm{O})$ \\
\hline 2ClCBA & 42 & 2927,2852 & 1719 & 1625 & 1282 \\
3ClCBA & 39 & 2963,2845 & 1712 & 1623 & 1273 \\
4ClCBA & 43 & 2965,2873 & 1716 & 1623 & 1281 \\
5ClCBA & 40 & $2953,2954,2873$ & 1713 & 1625 & 1285 \\
6ClCBA & 35 & $2953,2959,2856$ & 1711 & 1623 & 1281 \\
7ClCBA & 44 & $2953,2923,2852$ & 1717 & 1623 & 1289 \\
8ClCBA & 42 & $2953,2917,2852$ & 1717 & 1623 & 1298 \\
9CICBA & 54 & $2953,2917,2848$ & 1715 & 1623 & 1294 \\
10ClCBA & 62 & $2953,2917,2853$ & 1709 & 1624 & 1289 \\
11ClCBA & 52 & $2953,2917,2848$ & 1714 & 1625 & 1284 \\
12ClCBA & 67 & $2953,2916,2852$ & 1708 & 1625 & 1281 \\
13ClCBA & 43 & $2953,2917,2848$ & 1717 & 1623 & 1286 \\
14ClCBA & 52 & $2953,2917,2850$ & 1717 & 1620 & 1284 \\
15ClCBA & 57 & $2953,2917,2848$ & 1718 & 1623 & 1289 \\
16ClCBA & 64 & $2953,2916,2850$ & 1719 & 1625 & 1287 \\
\hline
\end{tabular}

thermogram of 11ClCBA upon heating and cooling cycles is shown in Figure 2.

\section{Discussion}

4.1. Physical Characterization. EI mass spectrum (Figure 1) showed the molecular ion peak at $\mathrm{m} / \mathrm{z}=413$ which was corresponding to molecular mass of $\mathrm{C}_{25} \mathrm{H}_{32} \mathrm{~N}_{1} \mathrm{O}_{2} \mathrm{Cl}$ suggesting that 11ClCBA was successfully synthesized.

Strong absorption bands appeared at 2917 and $2848 \mathrm{~cm}^{-1}$ in FTIR spectrum of 11ClCBA indicating the presence of aliphatic $\mathrm{C}-\mathrm{H}$ in alkyl chain. A sharp absorption band centered at $1284 \mathrm{~cm}^{-1}$ is attributed to $\mathrm{C}-\mathrm{O}$ bond. Absorption band emerged at $1625 \mathrm{~cm}^{-1}$ was designated for $\mathrm{C}=\mathrm{N}$ linking group. This value falls within the frequency range reported for Schiff base linkage $[19,20]$.

In ${ }^{1} \mathrm{H}$ NMR spectrum of 11ClCBA, two triplets appeared at $\delta=0.90 \mathrm{ppm}$ and $\delta=4.36 \mathrm{ppm}$, which can be ascribed to the methyl and methylene protons $\left(-\mathrm{OCH}_{2}-\right)$, respectively. The chemical shifts at $\delta=1.28-1.47 \mathrm{ppm}$ can be assigned to methylene protons of long alkyl chain $\left\{\mathrm{CH}_{3}-\left(\mathrm{CH}_{2}\right)_{8}-\right\}$. Four distinct doublets detected at $\delta=$ $7.19,7.39,7.98$, and $8.16 \mathrm{ppm}$ can be assigned to eight aromatic protons. A singlet was observed at the most downfield region; $\delta=8.33 \mathrm{ppm}$ is due to azomethine proton [13-15]. The molecular structure of 11ClCBA was further ascertained by using ${ }^{13} \mathrm{C}$ NMR spectroscopy. A signal at $\delta=14.08 \mathrm{ppm}$ is attributed to the methyl carbon, and peaks at $\delta=22.66-$ $31.89 \mathrm{ppm}$ are contributed to the methylene carbons of long alkyl chain. The signals appeared at $\delta=122.37-149.99 \mathrm{ppm}$ is belonged to twelve aromatic carbons. Azomethine carbon exhibited its signal at $\delta=159.41 \mathrm{ppm}$. The most downfield peak at $\delta=166.08 \mathrm{ppm}$ is due to the existence of carbonyl carbon of ester group.
TABLE 2: Transition temperature and associated enthalpy changes of alkyl 4-\{[(4-chlorophenyl)imino]methyl\}benzoates upon heating and cooling cycles.

\begin{tabular}{|c|c|}
\hline Compound & $\begin{array}{c}\text { Transition temperature, }{ }^{\circ} \mathrm{C}\left(\Delta H, \mathrm{~kJ} \mathrm{~mol}^{-1}\right) \\
\text { Heating } \\
{ }^{*} \text { Cooling }\end{array}$ \\
\hline 2ClCBA & $\begin{array}{l}\text { Cr } 117.3 \text { (25.5) I } \\
\text { Cr } 82.6(25.9) I\end{array}$ \\
\hline 3ClCBA & $\begin{array}{l}\text { Cr } 62.5(22.0) \mathrm{I} \\
\mathrm{Cr} 37.6(21.8) I\end{array}$ \\
\hline 4ClCBA & $\begin{array}{l}\text { Cr } 57.7 \text { (18.7) I } \\
\text { Cr } 31.8(17.2) I\end{array}$ \\
\hline $5 \mathrm{ClCBA}$ & $\begin{array}{l}\text { Cr } 55.8(23.6) \mathrm{I} \\
\text { Cr } 20.1(22.3) I\end{array}$ \\
\hline 6ClCBA & $\begin{array}{l}\text { Cr } 41.4(22.8) \mathrm{I} \\
\mathrm{Cr} 18.2(23.2) \mathrm{I}\end{array}$ \\
\hline 7ClCBA & $\begin{array}{l}\text { Cr } 46.6(24.4) \mathrm{I} \\
\mathrm{Cr} 21.3(25.3) \mathrm{I}\end{array}$ \\
\hline 8ClCBA & $\begin{array}{l}\text { Cr } 44.5(32.5) \mathrm{I} \\
\mathrm{Cr} 14.8(31.8) \mathrm{I}\end{array}$ \\
\hline 9ClCBA & $\begin{array}{l}\text { Cr } 53.3(41.3) \mathrm{I} \\
\operatorname{Cr} 25.6(34.1) I\end{array}$ \\
\hline 10ClCBA & $\begin{array}{l}\text { Cr } 53.1(42.9) \mathrm{I} \\
\text { Cr } 39.7(45.5) I\end{array}$ \\
\hline 11CICBA & $\begin{array}{l}\text { Cr } 63.1(45.8) \mathrm{I} \\
\mathrm{Cr} 42.1(49.0) \mathrm{I}\end{array}$ \\
\hline 12ClCBA & $\begin{array}{l}\text { Cr } 62.5 \text { (48.7) I } \\
C r 42.0(47.9) I\end{array}$ \\
\hline 13ClCBA & $\begin{array}{l}\text { Cr } 66.6(51.9) \mathrm{I} \\
\mathrm{Cr} 44.0(55.3) I\end{array}$ \\
\hline 14ClCBA & $\begin{array}{l}\mathrm{Cr} 70.3(49.1) \mathrm{I} \\
\mathrm{Cr} 47.7(51.3) \mathrm{I}\end{array}$ \\
\hline 15ClCBA & $\begin{array}{l}\text { Cr } 71.4(45.3) \mathrm{I} \\
\text { Cr } 50.1(50.3) I\end{array}$ \\
\hline 16ClCBA & $\begin{array}{l}\text { Cr } 75.6(61.8) \mathrm{I} \\
\text { Cr } 53.6(72.0) I\end{array}$ \\
\hline
\end{tabular}

Cr: crystal; I: isotropic. ${ }^{*}$ Cooling data is presented in italics font.

4.2. Phase Transition Behaviors and Optical Texture Studies. All the members in the $n \mathrm{ClCBA}$ series were nonmesogenic compounds. In the representative DSC thermogram of 11ClCBA (Figure 2), it showed an endotherm and exotherm, respectively, during both heating and cooling cycles. This observation indicates direct melting of crystal to isotropic liquid phase and vice versa. Under polarizing optical microscopy (POM) observation, The crystal changed to dark region isotropic during heating run. No liquid crystal texture was observed during cooling process. The rest of members showed similar characteristics as those found for 11ClCBA.

4.3. Effect of Alkyl Chain Length on Transition Temperatures. A further examination of DSC data also illustrates the evolution of the Cr-I transition with the lengthening of terminal chains. Based on phase transition data in Table 2, it can be deduced that the thermal properties were greatly influenced by the length of the terminal chains. Melting temperatures exhibited a typical descending trend as 


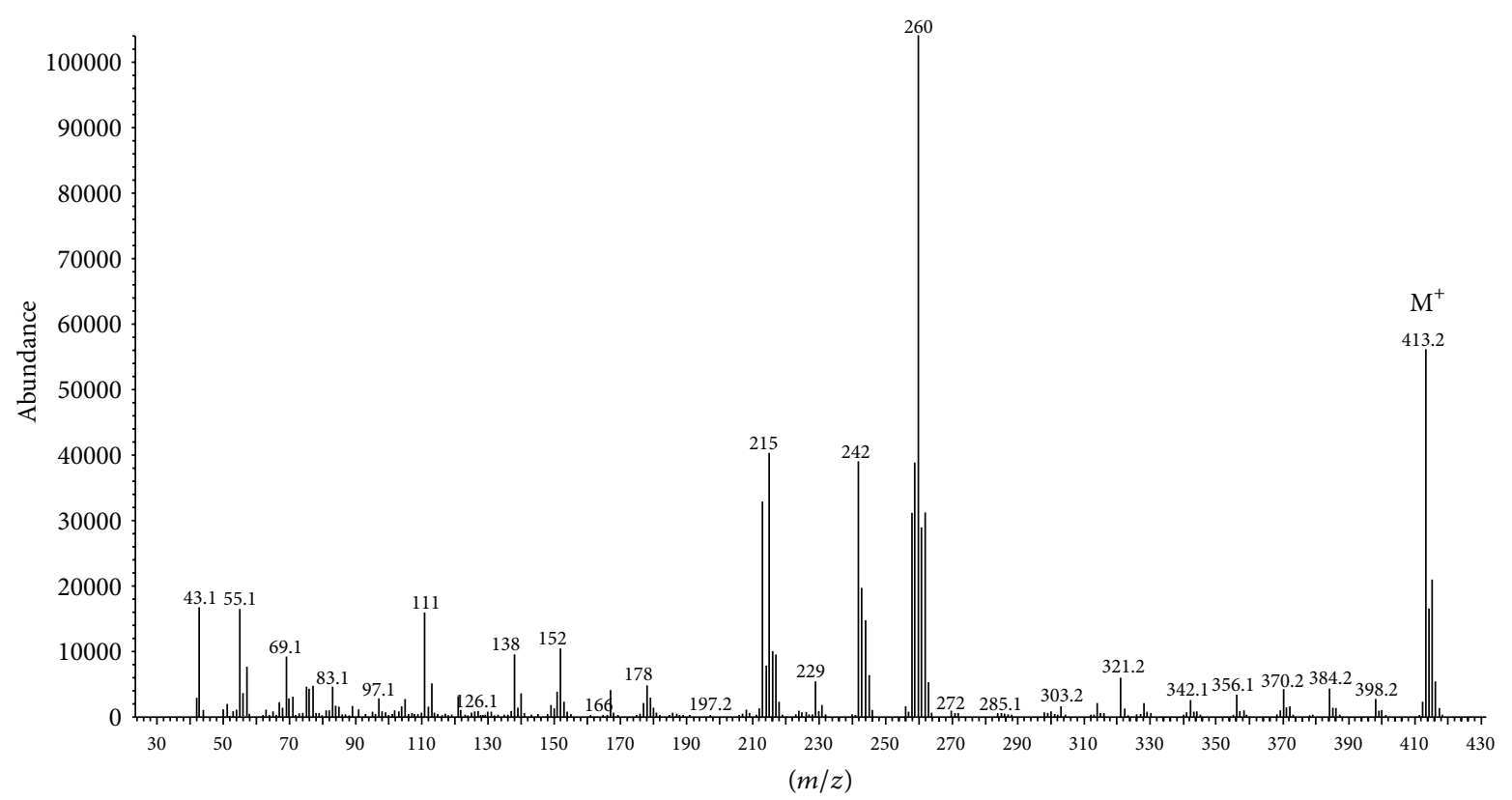

FIGURE 1: EI mass spectrum of undecyl 4-\{[(4-chlorophenyl)imino]methyl\}benzoate showing molecular ion peak $\left(\mathrm{M}^{+}\right)$.

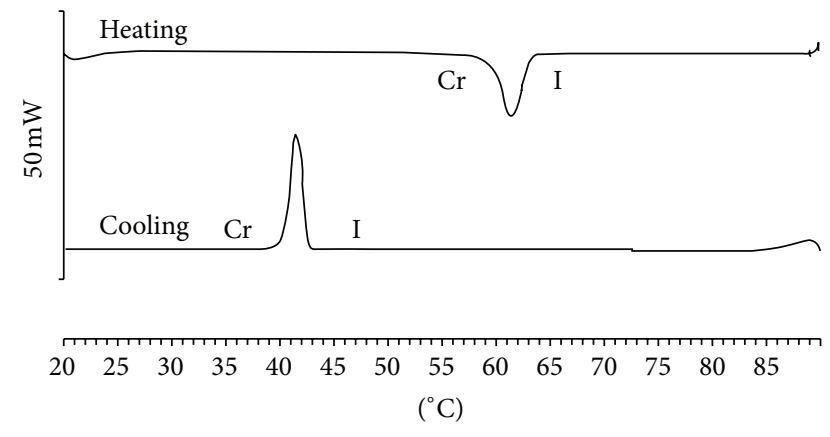

FIGURE 2: DSC thermogram of undecyl 4-\{[(4-chlorophenyl) imino]methyl\}benzoate during heating and cooling cycles.

the length of the carbon chain increased from the ethyl to the hexyl. This was attributed to the dilution of the mesogenic core, affected by the increase in the flexibility of the alkyl chain [21]. However, the lengthening of carbon chain from the hexyl to the pentadecyl derivatives led to ascending trend of melting temperatures. This phenomenon can be attributed to the increased intermolecular Van der Waals attraction [22]. A similar phenomenon was also reported for two analogous series of Schiff bases, 2hydroxy-4-methoxy- $4^{\prime}$-alkanoyloxyanilines and 3-methoxy4-alkanoyloxybenzylidene-4' -alkanoyloxyanilines [15]. The recrystallization points also show similar trend to that observed for melting temperatures.

4.4. Influence of Direction of Ester Linkage on Mesomorphism. Mesomorphic properties of two aromatic ring compounds, 4chlorobenzylidene-4' alkanoyloxyanilines (Series 1) [18] and alkyl 4-\{[(4-chlorophenyl)imino]methyl\}benzoates (Series
2), are strongly dependent on the direction of the ester linkage. Series 1 having molecular arrangement of alkylCOO-phenyl exhibited smectic A and B phases. However, Series 2 (present compounds) with the reversed ester linkage were nonmesomorphic compounds. The position of the ester linking group defines the direction of the carbonyl group. The different directions of the carboxyl groups between the phenyl and alkyl units cause significant changes on the dipole moment, which in turn result in a reduction of the polarizability anisotropy and geometric anisotropic of the molecule [23]. A similar phenomenon has been reported for some banana-type mesogens [16]. The smectic properties of the molecules are strongly affected not only by the electrostatic interactions but also by the geometrical circumstances [24]. In addition, Series 1 possessed higher melting point compared to Series 2 having the same number of carbons $(n)$ at the alkyl chain. This suggests that the direction of ester linkage can also change the thermal stability of a compound. The interaction between ester and phenyl groups in Series 1 seems to afford molecule with a higher polarity which would be expected to enhance lateral interactions of a polar nature and hence might lead to a higher clearing point (phase stability) [23].

\section{Conclusion}

Spectral, optical, and thermal behaviors of a homologous series of two aromatic ring compounds possessing chloroend group were studied. Melting and recrystallization points were greatly influenced by the changes of alkyl chain length. All compounds in $n \mathrm{ClCBA}$ series were nonmesomorphic derivatives. The orientation of ester linkage in $n$ ClCBA has significantly suppressed the formation of liquid crystal phase and thermal stability. 


\section{Acknowledgment}

The authors would like to thank Universiti Tunku Abdul Rahman for the research facilities and financial supports.

\section{References}

[1] F. Yuksel, D. Atilla, and V. Ahsen, "Synthesis and characterization of liquid crystalline unsymmetrically substituted phthalocyanines," Polyhedron, vol. 26, no. 15, pp. 4551-4556, 2007.

[2] B. Y. Zhang, F. B. Meng, M. Tian, and W. Q. Xiao, "Side-chain liquid-crystalline polysiloxanes containing ionic mesogens and cholesterol ester groups," Reactive and Functional Polymers, vol. 66, no. 5, pp. 551-558, 2005.

[3] P. J. Collings and M. Hird, Introduction to Liquid Crystals Chemistry and Physics, 43, Taylor and Francis, London, UK, 1990.

[4] S. Singh and D. A. Dunmur, Liquid Crystals: Fundamentals, 92, World Scientific Publishing, London, UK, 2002.

[5] H. Kelker and B. Scheurle, "A liquid-crystalline (nematic) phase with a particularly low solidification point," Angewandte Chemie, vol. 8, no. 11, pp. 884-885, 1969.

[6] B. E. Eran, A. Nesrullajev, and N. Y. Canli, "Characterization and investigation of the mesogenic, thermo-morphologic and thermotropic properties of new chiral $(S)$-5-octyloxy-2-[\{4-(2methylbuthoxy)-phenylimino(methyl]phenol liquid crystalline compound," Materials Chemistry and Physics, vol. 111, no. 2-3, pp. 555-558, 2008.

[7] S. T. Ha, L. K. Ong, S. T. Ong et al., "Synthesis and mesomorphic properties of new Schiff base esters with different alkyl chains," Chinese Chemical Letters, vol. 20, no. 7, pp. 767-770, 2009.

[8] S. T. Ha, G. Y. Yeap, and P. L. Boey, "Synthesis and liquid crystalline properties of new Schiff bases $N$-[4-(4-nalkanoyloxybenzoyloxy)benzylidene]-4-cyano-, 4-hydroxy-, 4thio-and 4-nitroanilines," Australian Journal of Basic \& Applied Sciences, vol. 3, no. 4, p. 3417, 2009.

[9] M. Parra, J. Vergara, C. Zuniga, E. Soto, T. Sierra, and J. L. Serrano, "New chiral Schiff's bases with a 1,3,4-thiadiazole ring in the mesogenic core: synthesis, mesomorphic and ferroelectric properties ," Liquid Crystals, vol. 32, no. 4, pp. 457-462, 2004.

[10] A. K. Prajapati and M. C. Varia, "Azomesogens with polar chloro, nitro and phenolic-OH substituents," Liquid Crystals, vol. 35, no. 11, pp. 1271-1277, 2008.

[11] R. Vora, A. K. Prajapati, and J. Kevat, "Effect of terminal branching on mesomorphism," Molecular Crystals and Liquid Crystals Science and Technology A, vol. 357, no. 1, pp. 229-237, 2001.

[12] G. Y. Yeap, S. T. Ha, P. L. Lim et al., "Synthesis and mesomorphic properties of Schiff base esters ortho-hydroxypara-alkyloxybenzylidene-para-substituted anilines," Molecular Crystals and Liquid Crystals, vol. 423, no. 1, pp. 73-84, 2004.

[13] G. Y. Yeap, S. T. Ha, P. L. Boey, W. A. K. Mahmood, M. M. Ito, and Y. Youhei, "Synthesis and characterization of some new mesogenic schief base esters $N$-[4-(4-nhexadecanoyloxybenzoyloxy)-benzylidene]-4-substituted anilines," Molecular Crystals and Liquid Crystals, vol. 452, no. 1, pp. 73-90, 2006.

[14] G. Y. Yeap, S. T. Ha, P. L. Lim et al., "Nematic and smectic a phases in ortho-hydroxy-para-hexadecanoyloxbenzylidenepara-substituted anilines," Molecular Crystals and Liquid Crystals, vol. 452, no. 1, pp. 63-72, 2006.
[15] G. Y. Yeap, S. T. Ha, P. L. Lim et al., "Synthesis, physical and mesomorphic properties of Schiff's base esters containing ortho-, meta- and para-substituents in benzylidene- $4^{\prime}$ alkanoyloxyanilines," Liquid Crystals, vol. 33, no. 2, pp. 205-211, 2006.

[16] S. A. R. Krishnan, W. Weissflog, G. Pelzl et al., "DFT and MD studies on the influence of the orientation of ester linkage groups in banana-shaped mesogens," Physical Chemistry Chemical Physics, vol. 8, no. 10, pp. 1170-1177, 2006.

[17] R. Deb, R. K. Nath, M. K. Paul et al., "Four-ring achiral unsymmetrical bent core molecules forming strongly fluorescent smectic liquid crystals with spontaneous polar and chiral ordered B7 and B1 phases," Journal of Materials Chemistry, vol. 20, no. 35, pp. 7332-7336, 2010.

[18] S. T. Ha, L. K. Ong, Y. Sivasothy et al., "Mesogenic Schiff base esters with terminal chloro group: synthesis, thermotropic properties and X-ray diffraction studies," International Journal of Physical Sciences, vol. 5, no. 5, pp. 564-575, 2010.

[19] B. Kosar, C. Albayrak, C. C. Ersanli, M. Odabasoglu, and O. Buyukgungor, "Molecular structure, spectroscopic investigations, second-order nonlinear optical properties and intramolecular proton transfer of (E)-5-(diethylamino)-2-[(4propylphenylimino)methyl]phenol: a combined experimental and theoretical study," Spectrochimica Acta A, vol. 93, pp. 1-9, 2012.

[20] G. Kastas, "Investigating the prototropic tautomerism in (E)-2[(4-fluorophenyl)iminomethyl]-5-methoxyphenol compound for solid state and solvent media by experimental and quantum computational tools," Journal of Molecular Structure, vol. 1017, pp. 38-44, 2012.

[21] P. Berdague, J. P. Bayle, M. S. Ho et al., "New laterally aromatic branched liquid crystal materials with large nematic ranges," Liquid Crystals, vol. 14, no. 3, pp. 667-674, 1993.

[22] G. W. Gray, Molecular Structure and Properties of Liquid Crystals, Academic Press, London, UK, 1962.

[23] C. T. Liu, "Molecular structure and phasef transition of thermotropic liquid crystals," Molecular Crystals and Liquid Crystals, vol. 74, no. 1, pp. 25-37, 1981.

[24] Y. Sakurai, S. Takenaka, H. Miyake, H. Morita, and T. Ikemoto, "Molecular structure and smectic properties. Part 1. The effect of linkages on smectic A thermal stability in three aromatic ring compounds linked by ester groups," Journal of the Chemical Society, no. 9, pp. 1199-1204, 1989. 

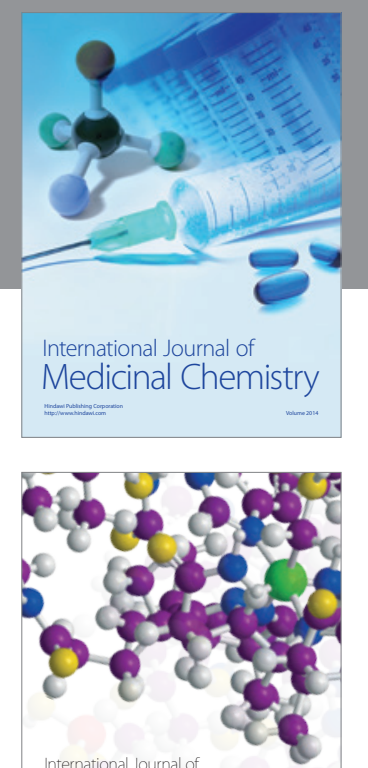

\section{Carbohydrate} Chemistry

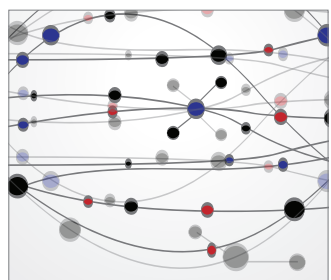

The Scientific World Journal
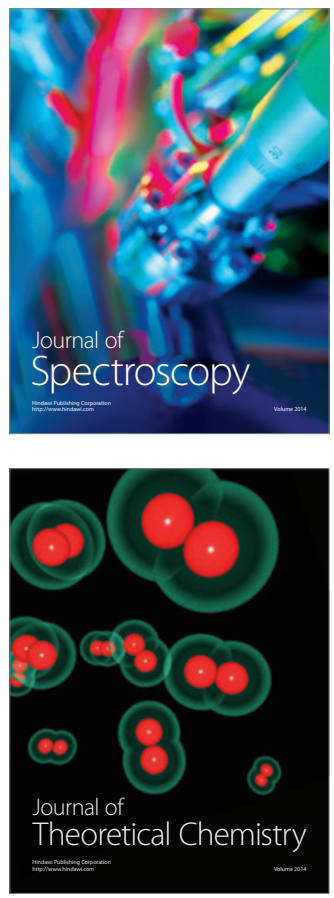
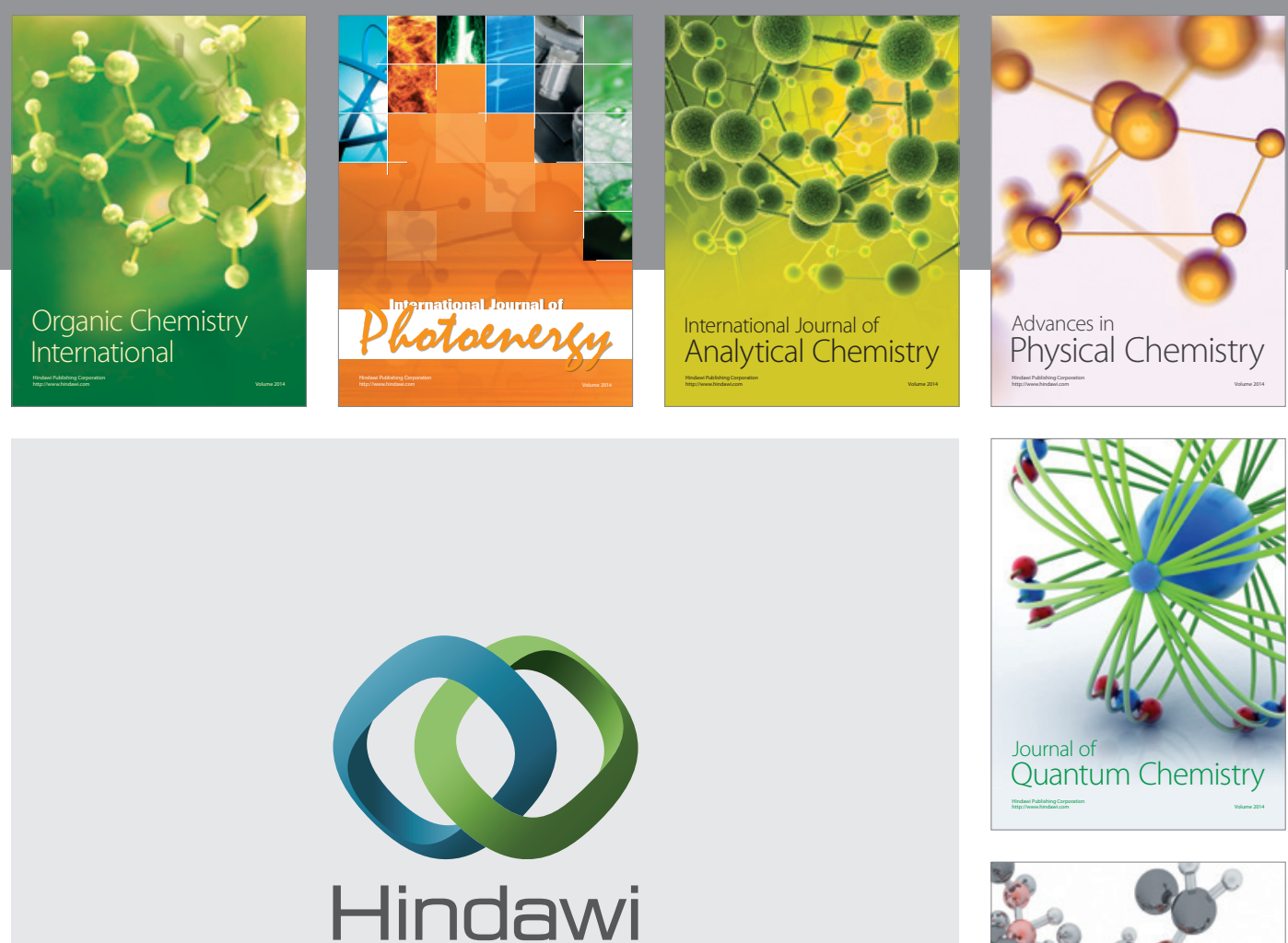

Submit your manuscripts at

http://www.hindawi.com

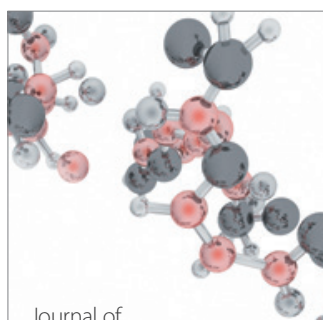

Analytical Methods

in Chemistry

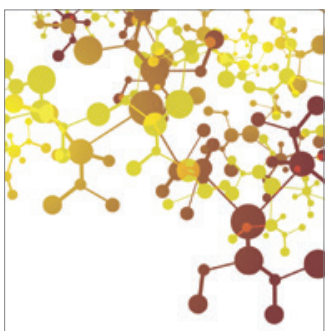

Journal of

Applied Chemistry

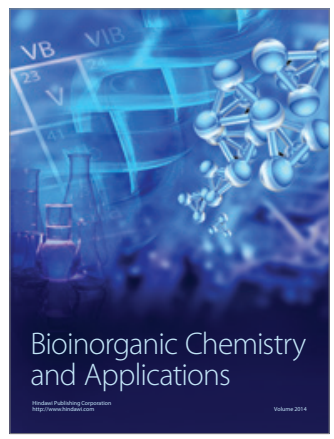

Inorganic Chemistry
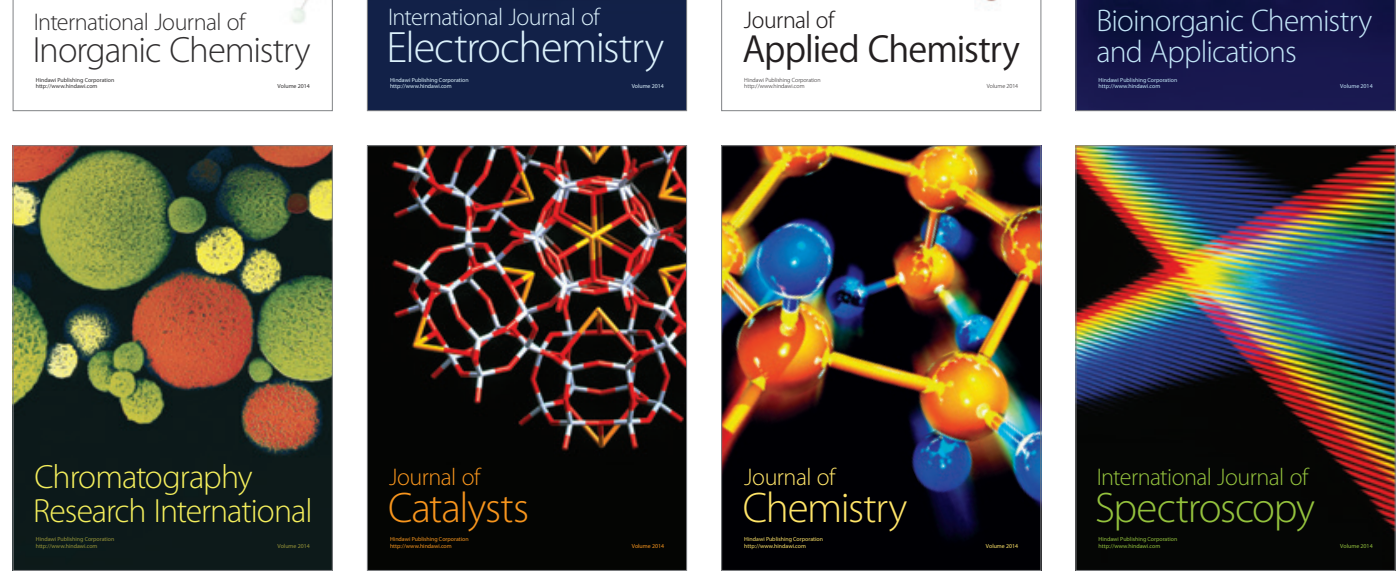